\title{
Avaliação toxicológica do Ginkgo biloba sobre a fertilidade e reprodução de ratos Wistar*
}

\author{
Toxicological evaluation of Ginkgo biloba in Wistar rat fertility and reproduction
}

\author{
Angela Pötter de Castro' ${ }^{1}$ Fernanda Bastos de Mello² \& João Roberto Braga de Mello
}

\begin{abstract}
RESUMO
Ginkgo biloba é uma planta usada como fitoterápico por demonstrar efeitos benéficos sobre algumas funções cerebrais, especialmente no tratamento das doenças de Alzeimer e Parkinson. Este trabalho teve por objetivo avaliar a toxicidade reprodutiva do extrato de Ginkgo biloba administrado em ratos Wistar. Os animais foram tratados diariamente por via oral, na dose de $17 \mathrm{mg} / \mathrm{kg}$ com auxílio de uma sonda orogástrica e os resultados comparados a um grupo controle tratado com solução fisiológica na dose de $10 \mathrm{~mL} / \mathrm{kg}$. Os machos de ambos os grupos foram tratados por 91 dias, e as fêmeas por 77 dias, no período de préacasalamento, acasalamento, gestação e lactação. Com relação ao desenvolvimento ponderal, consumo de água e ração os animais tratados com extrato de Ginkgo biloba não apresentaram alterações comparados ao grupo controle. Não foram detectadas alterações morfológicas nos órgãos internos, cuja massa relativa não diferiu do controle. Não houve interferência sobre a gestação, assim como os índices reprodutivos e de desenvolvimento pós-natal não apresentaram alterações significativas em relação ao grupo controle. A avaliação do líquido seminal do ducto deferente e dos testículos não mostrou diferença na morfologia espermática e na contagem de células espermáticas, comparadas ao grupo controle. Os filhotes de animais tratados com Ginkgo biloba apresentaram desenvolvimento pós-natal com aparecimento de características de desenvolvimento sexual dentro do período previsto para a espécie. De acordo com os resultados obtidos, conclui-se que o extrato de Ginkgo biloba em dose 10 vezes a recomendada com finalidade terapêutica, não possui efeito negativo na reprodução de ratos. O fitoterápico pode ser considerado atóxico sobre a reprodução de ratos.
\end{abstract}

Descritores: Ginkgo biloba, toxicidade reprodutiva, fitoterápico.

\section{ABSTRACT}

Ginkgo biloba is a plant used as phytotherapic based in benefic cerebral effects, specialy in the treatment of Alzeimer and Parkinson disease. In this study we investigated the potencial reproductive toxicity of a Ginkgo biloba extract in Wistar rats. The animals received daily per os $17 \mathrm{mg} / \mathrm{kg}$ of the extract and the results were compared to a control group (saline - $10 \mathrm{~mL} / \mathrm{kg}$ ). Mature male rats were treated over a period of 91 days, while the female rats were treated during the pre-mating, mating, pregnancy and lactation periods (77 days). The daily evaluation of body weight, water and food consumptiom did not show any difference between the Ginkgo biloba and the control group. No morphological alteration on visceral organ was observed, and the relative weight was similar to the control. The pregnancy was not affected and the dams gave birth to normal litters. The reproductive and post-natal index didn't show significant differences between groups. The seminal fluid evaluation didn't show differences between Ginkgo biloba and control group in spermatic count and morphology. The general and sexual development of the Ginkgo biloba offspring was normal, considering the specie. It is concluded that the administration of the Ginkgo biloba extract, 10 times the proposed therapeutic dose did not affect rat reproduction. The phytotherapic can be considered no toxic in rata reproduction.

Key words: Ginkgo biloba, reproductive toxicity, phytoterapic. 


\section{INTRODUÇÃO}

Em todo o mundo a utilização de plantas medicinais vem sendo realizada como recurso terapêutico, tanto na terapêutica humana como veterinária. No Brasil a utilização obteve sua oficialização (através da Farmacopéia Brasileira) em 1929. Em países como, Alemanha, China e França, este recurso representa cerca de $25 \%$ do arsenal Terapêutico. Nos países em desenvolvimento (75\% da população mundial), o porcentual chega a $80 \%$ do arsenal terapêutico [9]. Os fitoterápicos sofrem uma grande restrição quanto ao uso e aceitação, devido ao reduzido número de estudos que comprovam sua ação biológica e segurança quanto a efeitos tóxicos agudos, crônicos ou sobre a reprodução $[9,10]$. Os estudos toxicológicos têm a finalidade de avaliar a idéia errônea de que produtos fitoterápicos, por serem naturais, são isentos de efeitos tóxicos ou adversos, e que o uso popular de plantas medicinais serve como validação da eficácia de tais medicamentos [4]. O extrato das folhas de Ginkgo biloba é mundialmente utilizado por apresentar efeitos benéficos sobre algumas funções cerebrais. Seu extrato padronizado (EGb 761) tem sido mencionado como possibilidade terapêutica para muitas seqüelas ou danos causados por doenças neurodegenerativas [1-3].

Apesar da utilização generalizada de Ginkgo bi$l o b a$, não existem relatos sobre sua atividade toxicológica, especialmente a toxicidade crônica e reprodutiva. O presente trabalho avaliou o efeito deste fitoterápico sobre a fertilidade e reprodução de ratos Wistar, usando o "segmento I" recomendado pela Food and Drug Administration (FDA) e Organization for Economic Cooperation and Development (OECD) para investigação de substâncias com ação sobre a reprodução.

\section{MATERIAIS E MÉTODOS}

O extrato de Ginkgo biloba, EGb 761, lote piloto nº 99001, de procedência Centroflora, lote L980913, foi fornecido pelo laboratório Galenogal Farma, responsável pela garantia de pureza do produto testado. A composição declarada do extrato seco liofilizado de Ginkgo biloba é: $24 \%$ de glicosídeos flavonóides, $6 \%$ de terpenos e excipientes como lactose, amido de milho, povidona, estearato de magnésio e talco.

Foram utilizados 80 ratos albinos Wistar de ambos os sexos, sendo 10 machos e 30 fêmeas para cada grupo, com idade aproximada de 120 dias, provenientes do Centro de Criação e Experimentação de Animais de Laboratório da UFRGS, com condições constantes de umidade, temperatura $\left(21^{\circ} \mathrm{C} \pm 2\right)$ e ciclo de claro/escuro de 12 horas (claro das 9 às 21h), alimentados com ração comercial ${ }^{1}$ e água à vontade durante todo o período experimental. Os animais foram divididos aleatoriamente em dois grupos experimentais, contendo 10 machos e 30 fêmeas em cada grupo. Todos receberam tratamento diário por via oral com auxílio de uma sonda oro-gástrica, nas dosagens: grupo Ginkgo biloba dosagem diária de $17 \mathrm{mg} / \mathrm{kg}$ de massa corporal, equivalente a 10 vezes a dosagem recomendada para seres humanos e um grupo controle tratado com solução fisiológica na dosagem de $10 \mathrm{mg} / \mathrm{kg}$ de massa corporal. Os machos foram tratados por 70 dias antes do acasalamento. As fêmeas foram tratadas por 14 dias prévios ao acasalamento, durante o acasalamento, gestação e lactação (21 dias).

O período de acasalamento teve duração de 21 dias, correspondente a três ciclos de cinco dias consecutivos, com intervalo de 48 horas entre cada um dos ciclos. Na caixa de cada um dos machos, foram introduzidas três fêmeas virgens, permanecendo com eles durante as duas últimas horas do período de escuro (entre 7 e 9 hs). Após este período os animais foram separados e a constatação da prenhez foi realizada pela presença de espermatozóides no esfregaço vaginal, realizado diariamente e analisado ao microscópio óptico com aumento de dez vezes. Foi considerado primeiro dia de gestação, vinte e quatro horas após a constatação de esfregaço vaginal positivo.

Nos machos foram avaliadas as seguintes variáveis:

- massa corporal diária (g) durante 91 dias (antes e durante o acasalamento);

- consumo diário de ração (g) e água (ml) antes do acasalamento;

- peso relativo (\%) das vísceras no dia do sacrifício (fígado, baço, rins, coração, vesícula seminal, próstata e epidídimo);

- análise histopatológica dos órgãos enviados;

- número total de espermátides;

- produção diária de espermatozóides;

- porcentual de alterações morfológicas nos espermatozóides e

- aparecimento de sinais de toxicidade sistêmica como: perda de peso progressiva e redução na ingestão de água e ração.

Nas fêmeas foram avaliados:

- massa corporal diária em (g) durante o pré-acasalamento, gestação e lactação; 
- consumo diário de ração $(\mathrm{g})$ e água $(\mathrm{ml})$ durante o préacasalamento e gestação;

- peso relativo em (\%) dos órgãos ao final da lactação (fígado, rins, baço, coração, ovários e útero);

- sinais de aborto, distocia e prolongamento do período gestacional;

- número de implantes uterinos;

- análise das taxas reprodutivas;

- análise histopatológica dos órgãos enviados e

- sinais de toxicidade sistêmica como: perda de peso progressiva e redução na ingestão de água e ração.

Nos filhotes avaliou-se:

- alterações macroscópicas externas em todos os filhotes nascidos;

- número de filhotes por ninhada;

- número de machos e fêmeas nascidos;

- número de filhotes nascidos vivos;

- número de filhotes nascidos mortos;

- peso individual dos filhotes ao nascer;

- peso individual dos filhotes nos dias 0, 7, 14 e 21; e

- desenvolvimento físico de características gerais e sexuais dos filhotes.

Os dados foram analisados por análise de variância (ANOVA). O teste de Tukey foi usado para identificar diferenças entre grupos. As porcentagens foram analisadas pelo teste Qui-quadrado. Adotou-se como estatisticamente significativo o nível de 5\% [5].

\section{RESULTADOS}

Não foram observadas alterações significativas nos ratos tratados com Ginkgo biloba em comparação aos animais do grupo controle, quanto ao desenvolvimento ponderal. As oscilações diárias no consumo de água e ração não mantiveram relação com o desenvolvimento ponderal dos animais. Não foram observadas alterações morfológicas nos órgãos internos, cuja massa relativa não difere significativamente do controle (Tabela 1).

O exame do líquido seminal do ducto deferente e dos testículos não mostrou diferenças na morfologia espermática ou na contagem de células espermáticas do grupo Ginkgo biloba comparado ao controle (Tabela 2).

As fêmeas tratadas durante os períodos de préacasalamento, acasalamento, gestação e amamentação não apresentaram alterações comportamentais ou de respiração que indicassem toxicidade do fitoterápico.

Não se observou alterações morfológicas nos órgãos internos, cuja massa relativa não diferiu significativamente do controle (Tabela 3 ).
As fêmeas apresentaram tempo de gestação conforme o previsto (21 a 23 dias), não havendo diferença significativa sobre a gestação. Número e massa corporal de filhotes normais, não diferindo significativamente das fêmeas usada no grupo controle. Consumo de água e ração e desenvolvimento ponderal não apresentaram qualquer diferença significativa.

Os índices reprodutivos e de desenvolvimento pós-natal não apresentaram alterações significativas em relação ao grupo controle (Tabela 4).

As proles nascidas de ratas tratadas durante $\mathrm{o}$ pré-acasalamento, acasalamento, gestação e lactação, não

Tabela 1. Massa relativa dos órgãos (\%) dos machos tratados durante 91 dias consecutivos com extrato de Ginkgo biloba na dose de $17 \mathrm{mg} / \mathrm{kg}$ e um grupo controle tratado com solução fisiológica na dosagem de $10 \mathrm{~mL} / \mathrm{kg}$. São apresentados os valores médios \pm epm.

\begin{tabular}{lcc}
\hline $\begin{array}{c}\text { Massa relativa } \\
\text { dos órgãos }(\%)\end{array}$ & $\begin{array}{c}\text { Controle } \\
\mathbf{n}=10\end{array}$ & $\begin{array}{c}\text { Ginkgo biloba } \\
\mathbf{n}=10\end{array}$ \\
\hline Coração & $0,38 \pm 0,01$ & $0,35 \pm 0,007$ \\
Baço & $0,15 \pm 0,01$ & $0,14 \pm 0,004$ \\
Fígado & $3,48 \pm 0,08$ & $3,38 \pm 0,04$ \\
Rim direito & $0,32 \pm 0,01$ & $0,33 \pm 0,01$ \\
Rim esquerdo & $0,32 \pm 0,006$ & $0,33 \pm 0,01$ \\
Testículo direito & $0,36 \pm 0,01$ & $0,37 \pm 0,008$ \\
Testículo esquerdo & $0,37 \pm 0,009$ & $0,37 \pm 0,008$ \\
Epidídimo direito & $0,15 \pm 0,006$ & $0,15 \pm 0,004$ \\
Epidídimo esquerdo & $0,15 \pm 0,003$ & $0,16 \pm 0,003$ \\
Vesícula seminal vazia & $0,14 \pm 0,004$ & $0,12 \pm 0,009$ \\
Próstata & $0,13 \pm 0,01$ & $0,15 \pm 0,01$ \\
\hline $\mathrm{n}=$ número de animais por & grupo. &
\end{tabular}

Tabela 2. Índices de fertilidade dos ratos tratados durante 91 dias consecutivos com extrato de Ginkgo biloba $17 \mathrm{mg} / \mathrm{kge}$ um grupo controle tratado com solução fisiológica na dosagem de $10 \mathrm{~mL} / \mathrm{kg}$. São apresentados os valores médios \pm epm.

\begin{tabular}{|c|c|c|}
\hline & $\begin{array}{c}\text { Controle } \\
n=30\end{array}$ & $\begin{array}{l}\text { Ginkgo biloba } \\
\mathrm{n}=30\end{array}$ \\
\hline $\begin{array}{l}\text { Produção diária de } \\
\text { espermatozóides }\left(x 10^{6}\right)^{*}\end{array}$ & $27,2 \pm 2,1$ & $27,93 \pm 3,8$ \\
\hline $\begin{array}{l}\text { Número de } \\
\text { espermatozóides }\left(\times 10^{6}\right)^{* *}\end{array}$ & $176,7 \pm 27,1$ & $203,6 \pm 35,2$ \\
\hline $\begin{array}{l}\text { Espermatozóides } \\
\text { anormais (\%) }\end{array}$ & $5,7 \pm 0,8$ & $5,4 \pm 1,0$ \\
\hline \multicolumn{3}{|c|}{$\begin{array}{l}\text { "A produção diária de espermatozóides foi medida a partir da conta- } \\
\text { gem de células espermáticas em câmara de Neubauer, a partir de } \\
\text { macerados de testículos. Mello, } 2001 \text { [4]; " } \text { "O número de espermatozói- } \\
\text { des foi definido a partir de sua contagem em alíquota do macerado da } \\
\text { cauda do epidídimo em câmara de Neubauer. Mello, } 2001 \text { [4]. }\end{array}$} \\
\hline
\end{tabular}


tilidade dos machos indicam para a inexistência de toxicidade reprodutiva para os ratos tratados com Ginkgo biloba.

As taxas reprodutivas proporcionam em conjunto um excelente indicador da interferência de diferentes substâncias químicas sobre a reprodução, podendo inclusive identificar o período no qual os efeitos tóxicos reprodutivos ocorreram [8]. Não foram observadas diferenças estatisticamente significativas nas taxas reprodutivas dos animais tratados com Ginkgo biloba, o que reitera a ausência de toxicidade reprodutiva.

Durante a gestação, o peso das ninhadas pode ser influenciado pela capacidade intra-uterina, pelo tamanho da ninhada e pela duração da gestação. Após o nascimento, além da habilidade da fêmea, o efeito de substâncias químicas pode comprometer o desenvolvimento [6]. No caso dos filhotes de ratos tratados com Ginkgo biloba não foram observadas alterações no desenvolvimento ponderal e geral dos filhotes, descida de testículos à bolsa escrotal, separação prepucial e abertu- ra do canal vaginal. Portanto, os resultados não evidenciam interferência de Ginkgo biloba sobre o desenvolvimento das proles.

\section{CONCLUSÕES}

Pode-se concluir que a administração do extrato seco liofilizado de Ginkgo biloba, na dose de $17 \mathrm{mg} / \mathrm{kg}$ em ratos Wistar, não interfere na reprodução e no desenvolvimento ponderal de machos, fêmeas e características sexuais e de desenvolvimento dos seus filhotes.

Considerando que o índice terapêutico é a relação entre DL50 e DE50, podemos concluir que o índice do extrato seco liofilizado de Ginkgo biloba para ratos é maior que 10 .

Os resultados permitem concluir que o extrato seco liofilizado de Ginkgo biloba pode ser considerado praticamente atóxico.

\section{NOTA INFORMATIVA}

${ }^{1}$ Nuvilab CR1 - Nuvital, Colombo/PR.

\section{REFERÊNCIAS}

1 Defeudis F.V. 1991. Ginkgo biloba Extract (Egb 761): Pharmacological Activities and Clinical Application. Paris: Elsevier, 201p.

2 Diamond B.J., Shiflett S.C., Feiwel N., Matheis R.J., Noskin O., Richards J.A. \& Schienberger N.E. 2000. Ginkgo biloba extract: mechanisms and clinical indication. Archives of Physical Medicine \& Rehabilitation. 81: 668-678.

3 Kleijnen J. \& Knipschild P. 1992. Ginkgo biloba. The Lancet. 340: 1136-1139.

4 Lapa A.J. 1999. Farmacologia e toxicologia de produtos naturais. In: Simões C.M.O. (Ed). Farmacognosia da planta ao medicamento. Florianópolis: Editora da Universidade Federal de Santa Catarina, pp.181-196.

5 Lapponi J.C. 2000. Estatística usando o Excel. São Paulo: Lipponi, 451p.

6 Mello F.B. 2001. Estudo dos efeitos de Lantana camara (Verbenaceae) sobre a fertilidade e reprodução de ratos. 120f. Porto Alegre, RS. Dissertação (Mestrado em Ciências Veterinárias) - Programa de Pós-graduação em Ciências Veterinárias, Universidade Federal do Rio Grande do Sul.

7 Oga S. 1996. Fundamentos de Toxicologia. São Paulo: Atheneu, 515p.

8 Osweiller G.D. 1998. Toxicologia Veterinária. Porto Alegre: Artes Médicas, 526p.

9 Sharapin N. 1999. Medicinal plants: pharmacopoeial prescriptions. Anais da Academia Brasileira de Ciências. 71: $295-298$.

10 Sonaglio D. 1987. Padronização do extrato hidroalcóolico das sumidades floridas de Achyroclines saturcordes (LAM) D. C. Compositae (Marcela). 163f. Porto Alegre, RS. Dissertação (Mestrado em Ciência Farmacêutica) - Curso de Pós-graduação em Ciência Farmacêutica, Universidade Federal do Rio Grande do Sul.

11 Thomas J.A. 1989. Toxic responses of the reproductive system. In: Klaassen C.D. (Ed). Toxicology - The Basis Science of Poison. New York: Thieme Medical, pp.547-581.

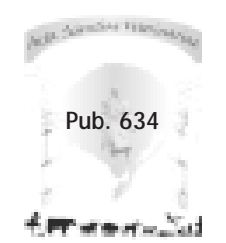

